\title{
A Comparison of Social (Weekend) Smokers, Regular (Daily) Smokers and a Never-Smoked Group Upon Everyday Prospective Memory
}

\author{
Tom Heffernan* and Terence O’Neill
}

\author{
Collaboration for Drug and Alcohol Research (CDAR), Department of Psychology, Northumbria University, Newcastle- \\ upon-Tyne, NE1 8ST, UK
}

\begin{abstract}
Our previous studies suggested that smokers have a worse performance on everyday prospective memory (PM) tasks than non-smokers. The present study compared regular and social smokers to see if there is a dose-response relationship between smoking and PM. We recruited 28 social (weekend) smokers (SS), 28 regular (daily) smokers (RS) and 28 people who had never smoked (NS) from among social science students who reported no psychiatric or drug and alcohol problems. The participant's PM was assessed by means of a Prospective Remembering Video Procedure (PRVP). After controlling for between-group variations in weekly (moderate) alcohol use, mood and IQ, the findings revealed that NS performed better than RS $(\mathrm{F}=1.44, \mathrm{p}<0.01)$ and $\mathrm{SS}(\mathrm{F}=1.70, \mathrm{p}<0.01)$, with no significant difference between $\mathrm{RS}$ and SS $(F=1.00, p=.38)$.Smokers have a lower performance on our PM task than non-smokers, regardless of the type of smoking pattern.
\end{abstract}

Keywords: Social smokers, regular smokers, never-smoked group, prospective memory.

\section{INTRODUCTION}

Tobacco smoking leads to a range of adverse health consequences, including an array of cancers, respiratory complications and coronary heart disease $[1,2]$, but despite these facts being widely published many smokers continue to smoke. There are a range of cognitive deficits associated with prolonged smoking including deficits in psychomotor speed [3], verbal and visual memory [4, 5], working memory $[4,6-9]$ and executive function [10-13]. It should be noted that some of the previous research has shown mixed effects of smoking upon memory, including no change or enhancement [see e.g. 14, 15], however this early research was confounded by a lack of an adequate control group (i.e. the lack of a non-smoking comparison group) or had used deprived smokers (where the 'enhancement' shown in memory reflects a return to baseline cognitive performance following a period of smoking abstinence). In addition, this work has tended to focus on retrospective memory, with much less focus upon what impact prolonged smoking has upon everyday memory processes. One example of everyday memory is prospective memory (PM) - which refers to the cognitive ability to carry out particular planned action(s) at some future point(s) in time [16, 17]. PM is important because the successful management of everyday tasks is crucial to independent living [17] and problems with PM might best reflect the difficulties experienced by smokers in their daily lives. PM failures can seriously disrupt everyday living, ranging from the less serious forms (e.g. forgetting to post a birthday card on time), to very serious forms of lapses (e.g. forgetting to take an important medication on time).

*Address correspondence to this author at the Collaboration for Drug and Alcohol Research (CDAR), Department of Psychology, Northumbria University, Newcastle-upon-Tyne, NE1 8ST, UK; Tel: ++ 0191227 4037; Fax: ++ 0191227 3190; E-mail: tom.heffernan@northumbria.ac.uk
Only a handful of studies have focused on smoking-related PM deficits. In two of these studies smokers reported significantly more self-reported PM lapses (e.g. forgetting to meet with friends on time, posting letters on time) when compared with never-smoked groups $[18,19]$ and a further study found smoking-related PM deficits when compared with never-smoked group on an objective measure in the form of the Cambridge Prospective Memory Test which provided a laboratory-based measure of PM [20]. These findings were observed after controlling for a range of other factors, e.g. other drug use and mood. A recent focus in the smoking literature is the distinction between 'social' and 'regular' smoking as distinct patterns of smoking [see e.g. $21,22]$. A social smoker can be defined as a person who smokes a fairly large quantity of cigarettes in a short session (i.e. within a few hours) on a handful of occasions across the week (e.g. when going out at the weekend with friends). Regular smokers are those who smoke on a daily basis, regardless of any activity in which they are engaged. It has been suggested that social smokers exhibit a different psychobiological profile from regular smokers [22], but no work to date has compared social and regular smokers on cognition in general, or on everyday cognition in the form of prospective remembering. If the association between smoking and memory functioning is causal, we would expect a dose-response, i.e. a more severe deficit in heavier smokers compared to occasional smokers.

The current study therefore aims to address this by comparing 'social (weekend) smokers', 'regular (daily) smokers', and a never-smoked control group on an objective PM measure in the form of the Prospective Remembering Video Procedure (PRVP). The PRVP involves remembering a series of pre-determined location-action combinations whilst viewing a short CD clip of a busy shopping high street, giving the procedure ecological validity since it is more akin to remembering within a real-world context. The 
PRVP is based on a methodology used previously to reveal selective PM deficits in both cannabis users [23] and binge drinkers [24]. Other recreational drug use (e.g. alcohol, cannabis, ecstasy) were also measured and analysed - since these variables are known to affect PM performance independently $[25,26]$. Given that mood (e.g. anxiety, depression) can interact with drug use upon cognition and memory [27] and that mood has been shown to influence PM directly [28], this was also measured and its relationship to the main PM was analysed. Finally, variations in IQ were measured since this good performance on IQ (using the National Adult Reading Test) correlates well with good PM performance [29].

\section{METHODS}

\section{Participants}

One-hundred and forty undergraduate students studying on the first or second year of a social science degree (psychology, criminology, and sociology) were recruited from universities in the North East of England on a voluntary basis. The inclusion criteria were; a) that the person had never reported using any illegal substance (ecstasy, cannabis, etc.) alongside smoking, b) did not drink excessive amounts of alcohol i.e. more than the recommended 'safe' weekly limits or were/had been 'binge drinkers' [see 24] or had not used alcohol within the past 48-hours, c) reported that they had never suffered from a psychiatric condition (e.g. substance-dependence, clinical depression or amnesia). From the original 140 students screened, 93 were eligible to take part in the study, but to achieve balanced numbers across the three groups (social smokers, regular smokers, and a neversmoked group), a further 9 participants were randomly omitted from the data base. Eighty-four participants remained and 28 of these were classified as 'social smokers' (SS: defined as those who smoked on one or two occasions over the weekend), 28 were classed as 'social smokers' (SS: 19 females) who smoked an average of 21.4 cigarettes when going out on one or two occasions over the weekend, 28 'regular smokers' (RS: 22 females) who smoked an average of 10-15 cigarettes daily, and 28 who had never smoked any tobacco product (NS: 18 females). All of the smoking participants reported that they only smoked cigarettes and had smoked immediately before testing began in order to avoid any potential smoking withdrawal effects [30]. All participants were studying at university at the time of testing.
None of the participants reported having previously suffered from/or were currently suffering from any psychiatric condition. Descriptive statistics for age, weekly units of alcohol use, number of cigarettes smoked and smoking history are contained in Table $\mathbf{1}$.

\section{Measures and Procedure}

A Drug Use Questionnaire used in previous research [23, 24] measured smoking and other drug use, the Hospital Anxiety and Depression Scale [31] measured mood in terms of levels of anxiety and depression, and the National Adult Reading Test (NART) was administered during the study and provided a current measure of IQ [32]. Objective PM was measured by means of the PRVP which involved presenting a list of 16 specific locations (e.g. "When you reach the 'Next' store") accompanied by a list of associated actions (e.g. "Exchange a jumper you bought previously"), followed by an 8-minute CD clip of a busy shopping area of a UK city containing the pre-determined location-action combinations. The participant was instructed that he/she should only write down each location-action combination when the familiar location was reached on viewing the $C D$ clip and not before, to ensure that each combination was recalled as part of the ongoing PM task presented on the CD clip. Non-target distracter tasks (other shop fronts, passersby) were also included on the CD clip to ensure that the task was akin to real world prospective remembering. One point was given for each location-action combination correctly recalled, ranging from $0-16$, with the higher score indicating more proficient PM. The PRVP methodology has been used in previous research to uncover drug-related PM deficits in cannabis users and binge drinkers, and shows acceptable reliability $(\alpha=0.68)$ [see 23,24 ]. Individual testing took place in a quiet laboratory situation and testing time was approximately 30 minutes. Ethical approval was obtained from the School of Life Sciences Ethics Committee at Northumbria University.

\section{Data Analysis and Statistical Methods}

All data was entered into SPSS-16. An independent t-test compared the SS and RS groups in terms of length of smoking in years. Chi-square analysis was applied to compare the gender breakdown across the SS, RS and NS groups. A univariate analysis of co-variance (ANCOVA) was applied to compare the three groups on their

Table 1. Descriptive Data for the Social Smokers, Regular Smokers and Never Smoked Groups

\begin{tabular}{|c|c|c|c|c|}
\hline & Social Smokers (N=28) & Regular Smokers (N=28) & Never Smoked (N=28) & Between Group Differences \\
\hline \hline Age & $20.3(2.88)$ & $22.5(4.63)$ & $21.0(2.87)$ & $\mathrm{F}=2.55, \mathrm{P}=.08 \mathrm{~ns}$ \\
\hline Length of smoking (in years) & $6.55(5.67)$ & $7.93(5.21)$ & $\mathrm{N} / \mathrm{A}$ & $\mathrm{T}=0.94, \mathrm{p}=.34 \mathrm{~ns}$ \\
\hline Weekly alcohol use & $14.9(6.83)$ & $13.2(8.82)$ & $16.5(10.8)$ & $\mathrm{F}=0.94, \mathrm{P}=.39 \mathrm{~ns}$ \\
\hline HADS Anxiety & $7.14(3.13)$ & $8.79(3.46)$ & $7.79(3.52)$ & $\mathrm{F}=1.68, \mathrm{P}=.19 \mathrm{~ns}$ \\
\hline HADS Depression & $3.00(2.12)$ & $4.07(2.56)$ & $3.64(2.26)$ & $\mathrm{F}=1.50, \mathrm{P}=.19 \mathrm{~ns}$ \\
\hline NART IQ & $116(2.98)$ & $117(7.33)$ & $117(6.86)$ & $\mathrm{F}=2.21, \mathrm{P}=.11 \mathrm{~ns}$ \\
\hline PRVP & $8.96(2.51)$ & $8.71(2.29)$ & $10.3(1.91)$ & $\mathrm{F}=4.91, \mathrm{P}<.01$ \\
\hline
\end{tabular}

Means and standard deviations (in brackets) comparing SS, RS and NS groups on age, cigarettes per-week, length of smoking in years (smokers only), units of alcohol consumed per-week, scores on the HADS anxiety and depression scales, IQ (NART) and PRVP scores. The final column summarises the results of between groups analyses (F tests and t-test), identifying significant and non-significant between group differences. 
performance on the PRVP - controlling for age, weekly alcohol use, scores on the HADS anxiety and depression scales and IQ (NART).

\section{RESULTS}

Table 1 below contains the means and standard deviations (in brackets) for age, cigarettes smoked use per week, length of smoking (in years), weekly alcohol use (the number of UK alcohol units consumed per week), HADS depression and HADS anxiety scores, IQ (NART) scores and scores on the PRVP, comparing the SS, RS and NS groups. An independent t-test revealed no significant difference between the SS and RS in terms of length of smoking years $(t(54)=0.94, p=0.34)$. Chi-Square analysis revealed no significant difference in the number of males and females between the SS, RS and NS groups $\left(\chi^{2}(2)=1.48, p=0.57\right)$. A series of one-way ANOVAs reveal no between group differences on age, weekly alcohol use, HADS anxiety, HADS depression and NART scores ( $\mathrm{p}>.08$ in all cases). To control for between-groups variations in age, weekly alcohol use (units), scores on the HADS anxiety and depression scales and IQ (NART), we used an analysis of co-variance (ANCOVA) comparing SS, RS and NS groups on the PRVP data. The ANCOVA revealed no relationships between weekly alcohol use and PRVP scores $(F(1,76)=0.53, p=$ $0.46)$, HADS anxiety and PRVP scores $(F(1,76)=2.57, p=$ $0.11)$, HADS depression and PRVP scores $(F(1,76)=2.09$, $p=0.15)$ or IQ and PRVP scores $(F(1,76)=0.07, p=0.78)$, but age did produce an independent impact upon PRVP scores $(F(1,76)=4.41, p<.05)$. After controlling for variations in these covariates the ANCOVA revealed a significant between-group main effect in terms of PRVP scores $(F(1,76)=4.91, p<.01)$. It should be noted that the between groups difference remained significant with the removal of the covariates form the analysis of variance test $(F(1,81)=4.52, p<.01)$. Pairwise comparisons revealed that the NS group performed significantly better than SS group $(F=1.70, \mathrm{p}<0.01)$ and the $\mathrm{RS}$ group $(F=1.44$, $\mathrm{p}<0.01)$, with no difference between the SS and RS groups $(F=1.00, \mathrm{p}=.38)$.

\section{INSERT TABLE 1 HERE}

\section{DISCUSSION}

The study compared 'social smokers' (SS: those who smoked a fairly large quantity of cigarettes on one or two occasions at the weekends) with a group of regular smokers (RS: who smoked on a daily basis) and a never-smoked (NS) control group to determine whether particular smoking patterns (SS and RS) has a differential impact upon everyday PM. After omitting people who drank excessively, used other drugs or suffered from a psychiatric disorder, and after controlling for between-group variations in weekly (moderate) alcohol use, mood and IQ, the findings revealed that both SS and RS performed significantly worse on the PRVP than NS, with no differences between the SS and RS groups. The finding that smokers performed worse on an objective PM task (the PRVP) when compared with a neversmoked group is consistent with previous research [18], but importantly reveals a lack of dose-response, which reduces the likelihood that the observed relationship is causal, although it does not rule out such a possibility altogether.
Smoking-related memory decline in general has been linked with increases in accelerated cerebral degeneration, such as brain shrinkage and atrophy $[33,34]$ and recent evidence has highlighted links between dangerous carcinogens in tobacco smoking and neuronal damage in the mammalian brain [35]. It is feasible that, given the links between PM and activity in the prefrontal/frontal regions of the brain [36, 37] there is smoking-related damage at the cerebral, or even neuronal levels.

\section{LIMITATIONS AND FUTURE DIRECTIONS}

There are a number of limitations to this study. A sample of students may not be representative of smokers in general. The use of self-reported smoking rate can be problematic, for example, participants who reported only occasional smoking may in fact smoke regularly. Future studies should use objective measures of smoke intake such as expired air carbon monoxide levels. Although the present study used the PRVP (and previous work has used the CAMPROMPT) to assess everyday PM, both of these tasks are laboratory-based methods and recent thinking in the PM field has emphasised the need to utilise actual real-world PM tasks [17]. Also, the reliability of the PRVP (Cronbach's alpha level =.68) is modest. In addition, we found no relationship between the performance on PRVP and the NART, although memory would normally be expected to correlate with IQ [see 29]. The fact that we replicated the previous finding despite using a potentially weak measure, makes the results more noteworthy, but it also suggests that further studies are needed and some caution needs to be exercised in interpreting our findings.

Future research should explore smoking-related PM deficits using a real world methodology - for example, an actual shopping trip scenario along an actual busy shopping high street. It could also be argued that the PRVP only provides a 'snapshot' of everyday memory while in reality PM is often carried out over prolonged delays (such as hours, days, or weeks). Future research should vary the task duration. Finally, given that in the UK smokers and nonsmokers differ in terms of a range of factors [see e.g. 38] including mental health, socioeconomic status and lifestyle variables (diet, exercise) it is feasible that the current finding reflects such between-group differences. Future research should measure such variables and analyse their impact upon everyday prospective memory function.

\section{CONCLUSION}

In conclusion, this is the first study to compare SS, RS and NS groups in PM. We confirmed out previous findings showing that smokers have lower performance on a PM task than non-smokers, but we found no difference between regular and social smokers and thus failed to show a doseresponse. Further research is needed to help understand the observed link.

\section{ACKNOWLEDGEMENT}

None declared.

\section{CONFLICT OF INTEREST}

None declared. 


\section{REFERENCES}

[1] Mannino DM, Buist AS. Global burden of COPD: risk factors prevalence, and future trends. Lancet 2007; 370: 765-73.

[2] World Health Organisation. Report on the global tobacco epidemic. UK: WHO, 2008

[3] Whalley LJ, Fox HC, Deary IJ, Starr JM. Childhood IQ, smoking, and cognitive change from age 11 to 64 years. Addict Behav 2005; 30: 77-88.

[4] Fried PA, Watkinson B, Gray R. Neurocognitive consequences of cigarette smoking in young adults - a comparison with pre-drug performance. Neurotoxicol Teratol 2006; 28: 517-25.

[5] Richards M, Jarvis MJ, Thompson N, Wadsworth MEJ. Cigarette smoking and cognitive decline in midlife: evidence from a prospective birth cohort study. Am J Public Health 2003: 93: 9948.

[6] Ernst M, Heishman SJ, Spurgeon L, London ES. Smoking history and nicotine effects on cognitive performance. Neuropsychopharmacology 2001; 25: 313-90.

[7] Greenstein JE, Kassel JD. The effects of smoking and smoking abstinence on verbal and visuospatial working memory capacity. Exp Clin Psychopharmacol 2009; 17: 78-90.

[8] Jacobson LK, Mencl WE, Constable RT, Westerveld M, Pugh KR. Impact of smoking abstinence on working memory neurocircuitry in adolescent daily tobacco smokers. Psychopharmacology 2007; 193: $557-66$

[9] Spilich GJ, June L, Renner J. Cigarette smoking and cognitive performance. Brit J Addict 1992; 87: 1313-26.

[10] Glass JM, Buu A, Adams KM, et al. Effects of alcoholism severity and smoking on executive neurocognitive function. Addiction 2009; 104: 38-48

[11] Jacobson JL, Krystal JH, Mencl WE, Westervelt M, Frost SJ, Pugh KR. Acute and chronic effects of smoking on adolescent smokers. Biol Psychiatr 2005; 57: 56-66.

[12] Kalmijn S, van Botel MPJ, Verschuren MWM, Jolles J, Launer LJ. Cigarette smoking and alcohol consumption in relation to cognitive performance in middle age. Am J Epidemiol 2002; 156: 936-44.

[13] Tait RJ, Siru R. Executive cognitive function and cessation of smoking among older smokers. Aging Health 2009; 5: 33-7.

[14] Whittington JE, Huppert FA. Smoking and Cognitive Decline. Hum Psychopharmacol 1997; 12: 467-80.

[15] Roth N, Lutiger B, Hasenfratz M, Battig K, Knye M. Smoking deprivation in early and late smokers and memory functions. Psychopharmacology 1992; 106: 253-60.

[16] Brandimonte M, Einstein GO, McDaniel MA, Editors. Prospective memory: theory and applications. USA: Lawrence Erlbaum Associates, 1996.

[17] McDaniel MA, Einstein GO, Editors. Prospective memory: an overview and synthesis of an emerging field. UK: Sage, 2007.

[18] Heffernan TM, Ling J, Parrott AC, Buchanan T, Scholey AB, Rodgers J. Self-rated every day and prospective memory abilities of cigarette smokers and non smokers: a web based study. Drug Alcohol Depend 2005; 78: 235-41.

[19] Rash CJ. The effects of smoking and nicotine withdrawal on prospective memory. Unpublished $\mathrm{PhD}$ Dissertation. USA, Louisiana State University, 2007.
Heffernan TM, O’Neill T, Moss M. Smoking and everyday prospective memory: a comparison of self-report and objective methodologies. Drug Alcohol Depend 2010; 112: 234-8.

[21] Waters AJ, Sayette MA. Implicit cognition and tobacco addiction. In: R W Wiers, AW Stacy. (Eds.). Handbook of implicit cognition and addiction. 2006. London: Sage.

[22] Whitesel J. Social Smoking. Paper presented at the annual meeting of the American Sociological Association, Atlanta Hilton Hotel, Atlanta, GA, August 16, 2003.

[23] Bartholomew J, Holroyd S, Heffernan TM. Does cannabis use affect prospective memory in young adults? J Psychopharmaco 2010; 24: 241-6.

[24] Heffernan TM, Clark R, Bartholomew J, Ling J. Does binge drinking in teenagers affect their everyday prospective memory? Drug Alcohol Depend 2010; 109: 73-9.

[25] Heffernan TM. The impact of excessive alcohol use on prospective memory: a brief review. Curr Drug Abuse Rev 2008; 1: 36-41.

[26] Rodgers J, Buchanan T, Scholey AB, Heffernan TM, Ling J, Parrott AC. Prospective Memory: The Influence of Ecstasy, Cannabis and Nicotine Use and the WWW. Open Addic J 2011; 4 : 44-5

[27] Parrott AC, Morinan A, Moss M, Scholey A. Understanding Drugs and Behaviour. Chichester, UK: Wiley, 2004.

[28] Cuttler C, Graf P. Sub-clinical compulsive checkers show impaired performance on habitual, event- and time-cued episodic prospective memory tasks. Journal of Anxiety Disorders 2009; 23: 813-23.

[29] Brooks BM, Rose FD, Potter J, Jayawardena S, Morling A. Assessing stroke patients' prospective memory using virtual reality. Brain Inj 2004; 18: 391-401.

[30] Sakurai Y, Kanazawa I. Acute effects of cigarettes in non-deprived smokers on memory, calculation and executive functions. Hum Psychopharmacol 2002; 17: 369-73.

[31] Snaith RP, Zigmond AS. Hospital anxiety and depression scale. Windsor, NFER: Nelson, 1994.

[32] Nelson HE, Willison J. National Adult Reading Test (NART) manual (2nd Ed.). Windsor, UK. NFER: Nelson, 1991.

[33] Nooyens ACJ, van Gelder BM, Verschuren WMM. Smoking and Cognitive decline among middle-aged men and women: the Doetinchen cohort study. Am J Public Health 2008; 98: 1-7.

[34] Sabia S, Marmot M, Dufouil C, Singh-Manoux A. Smoking history and cognitive function in middle age from the Whitehall II study. Arch Intern Med 2008; 68: 1165-73.

[35] Ghosh D, Mishra MK, Das S, Kaushil DK, Basu A. Tobacco carcinogen induces microglial activation and subsequent neuronal damage. J Neurochem 2009; 110: 1070-81.

[36] Burgess PW, Scott SK, Frith CD. Role of the rostral frontal cortex (area 10) in prospective memory: a lateral vs medial dissociation. Neuropsychologia 2003; 41: 906-18.

[37] Simons JS, Scholvinck ML, Gilbert SJ, Frith CD, Burgess PW. Differential components of prospective memory? Evidence from fMRI. Neuropsychologia 2006; 44: 1388-97.

[38] McClure JB, Divine G, Alexander G, et al. A comparison of smokers' and non-smokers' fruit and vegetable intake and relevant psychosocial factors. Behav Med 2009; 35: 14-22.

This is an open access article licensed under the terms of the Creative Commons Attribution Non-Commercial License (http://creativecommons.org/licenses/ by-nc/3.0/) which permits unrestricted, non-commercial use, distribution and reproduction in any medium, provided the work is properly cited. 